\title{
Orthographies and their phonologies: A hypothesis
}

\author{
DEREK BESNER \\ University of Waterloo, Waterloo, Ontario, Canada
}

\begin{abstract}
Different orthographies produce qualitatively different phonological codes when subjects are forced to use a phonological code to access the lexical/semantic system. The phonological code that subserves the reading of syllabic Japanese is more closely tied to articulatory activity than is the phonological code utilized for reading alphabetic English. An experiment is suggested and described that would capitalize on characteristics of Serbo-Croatian orthography in order to discriminate among alternative accounts of this difference between the phonological readings of Japanese Kana and alphabetic English.
\end{abstract}

It is now a received idea that when people read, they translate marks on the page into some form of "phonological" representation-at least some of the time. This phonological representation may be used to access lexi$\mathrm{cal} /$ semantic memory and/or to function as a durable storage medium to help ongoing linguistic analyses of the text. The focus in this paper is on the nature of the phonological code that is used to access lexical or semantic memory, since it is now clear that when different orthographies are converted into phonology, the nature of the resulting phonological representations are not one and the same (see Besner, 1987a, for discussion).

One question of interest concerns how these representations differ; another is why. Some hypotheses are offered in response to both of these questions, but the main purpose of this note is to suggest an experiment whose outcome would shed some light on why these phonological representations differ. I first describe some experiments from the word recognition literature that offer a basis for the view that reading different orthographies leads to qualitatively different phonological representations. I then describe an experiment whose outcome would discriminate among alternative accounts of the emergence of these different phonological representations.

\section{THE DATA}

The typical experiment most immediately relevant to the topic under discussion has the subjects engage in a reading task wherein they are forced to use a phonological code in order to give a correct response, and performance is assessed under both quiet and dual task conditions. For example, subjects are asked to decide whether or not a printed letter string sounds like a real word (e.g., WAIJE-“"yes"; FAIJE-“"no") under both a quiet condition and one in which the subject counted aloud from 1

The author's mailing address is: Department of Psychology, University of Waterloo, Waterloo, Ontario N2L 3G1, Canada. to 10 (Baddeley \& Lewis, 1981; Besner, Davies, \& Daniels, 1981).

The subjects in this experiment can decide that the printed letter string (WAIJE) sounds like the real word (WAGE) only by converting it into phonology and then comparing it with phonological representations of words that are known to the reader and stored in lexical memory. With regard to the effects of carrying out a concurrent secondary task, it is now clear that occupying the articulatory apparatus (a technique hereafter referred to as "suppression") has no effect upon the time required to make such a decision when the letter strings are printed in English (see Besner, 1987a, 1987b, for a critique and a review of the limiting conditions).

This failure to find an effect of suppression when the letter strings are printed in English contrasts with results from an experiment by Kimura (1984) on native readers of Japanese. A brief description of the Japanese orthographies is necessary to flesh out the contrast with experiments on written English.

Written Japanese is composed of two distinct orthographies: Kanji, the logographic script used to represent content words, and Kana, the syllabic script. Kana is further divided into two: Katakana, the character script used to represent foreign loan words (e.g., computer, telephone), and Hirangana, the set typically used to represent grammatical morphemes (see, e.g., Sasanuma, 1984).

For present purposes, the important point is that all Kanji items can be (but rarely are) represented in either of the Kana scripts. This means that content words, when transcribed from Kanji into Kana, are orthographically, but not phonologically, unfamiliar. Such stimuli are therefore pseudohomophones in exactly the same sense that letter strings printed in English (e.g., BRANE) are pseudohomophones; they sound like real words, but are not spelled like real words known to the reader.

The contrast in the data between pseudohomophones written in Japanese and English can now be made clear. When Japanese subjects decide whether or not pseudohomophones presented in the Kana script are semantically 
related, suppression has a large and detrimental effect upon performance; response time is slowed (Kimura, 1984). When English-speaking subjects process pseudohomophones written in English (e.g., does this letter string sound like a real word?), there is no impairment due to suppression (Baddeley \& Lewis, 1981; Besner et al., 1981; see also Besner \& Davelaar, 1982; Besner, 1987b). It thus appears that phonology derived from one of the Japanese orthographies is more closely tied to articulatory activity than is phonology derived from English orthography. What is it about the nature of these two orthographies that gives rise to different forms of phonological representation?

One obvious difference between Kana and English is the nature of the relation between spelling and sound. Kana is syllabic; each character (mora) stands, roughly, for a syllable. Moreover, Kana is regular in the sense that a given character always stands for the same sound. English, in contrast, is alphabetic. It is also highly irregular in terms of spelling-sound correspondences. A standard example is the segment "ou," which can be pronounced several different ways (cough, bough, tough, dough). It is tempting to suppose that it is either the regular-irregular contrast or the syllabic-alphabetic contrast that is critical to explaining why performance with pseudohomophones written in Kana is grossly impaired by suppression, whereas performance with pseudohomophones written in English is unimpaired by suppression.

\section{SUGGESTED EXPERIMENT}

If one of these dimensions is critical, then a simple experiment provides a basis for teasing these factors apart, since written Serbo-Croatian is regular, but alphabetic. Since words are normally written in either the Roman or Cyrillic alphabets, mixing the two alphabets ${ }^{1}$ yields a letter string with unfamiliar spelling that nonetheless sounds like a real word (a pseudohomophone). All that remains is to determine whether performance on these pseudohomophones is impaired by suppression in lexical/semantic tasks (e.g., phonological-lexical decision; categorymembership judgments).

The experiment suggested here thus offers the possibility of disentangling some factors that may be causally related to the claim that different orthographies produce qualitatively different phonological codes to access the lexical-semantic system. Regularity may be critical, because the multiple possible spelling-sound correspondences in a deep orthography pressure the reading system to develop a level of representation removed from the rate-limiting step associated with the direct use of the articulators. Alternatively, awareness of phonemic structure, which appears necessary in order to learn to read alphabetic orthographies, marks a process of abstraction away from the articulators, whereas syllables are a natural unit for both speech perception and production.

If it is the regular-irregular contrast that is critical, then performance on pseudohomophones written in SerboCroatian would be expected to be impaired by suppression, since Kana, which is also regular, is heavily impaired by suppression. On the other hand, if it is the alphabetic-syllabic contrast that is important, then SerboCroatian ought to behave like English, and be unimpaired by suppression, since both English and Serbo-Croatian are alphabetic. All we need now is some data.

\section{REFERENCES}

BAdDEley, A. D., \& LEwIS, V. (1981). Inner active processes in reading: The inner voice, the inner ear and the inner eye. In A. M. Lesgold \& C. A. Perfetti (Eds.), Interactive processes in reading (pp. 107129). Hillsdale, NJ: Erlbaum.

BESNER, D. (1987a). On the relationship between orthographies and phonologies in visual word recognition. In A. Allport, D. MacKay, W. Prinz, \& E. Scheerer (Eds.), Language perception and production: Relationships between listening, speaking, reading and writing (pp. 211-226). London: Academic Press.

BesNer, D. (1987b). Phonology, lexical access in reading and articulatory suppression: A critical review. Quarterly Journal of Experimental Psychology, 39A, 467-478.

Besner, D., \& DAVelAAR, E. (1982). Basic processes in reading: Two phonological codes. Canadian Journal of Psychology, 36, 701-711.

BESNER, D., DAviES, J., \& DANiEls, S. (1981). Reading for meaning:

The effects of concurrent articulation. Quarterly Journal of Experimental Psychology, 33A, 415-438.

KimuRA, Y. (1984). Concurrent vocal interference: Its effects on Kana and Kanji. Quarterly Journal of Experimental Psychology, 36A, 117-132.

SaSANuma, S. (1984). Can surface dyslexia occur in Japanese? In L. Henderson (Ed.), Orthographies and reading. Hillsdale, NJ: Erlbaum.

\section{NOTE}

1. Using only those letters that are phonologically unambiguous in both scripts. 